\title{
The Neuronal Stress Response: Nuclear Translocation of Heat Shock Proteins as an Indicator of Hyperthermic Stress
}

\author{
P. Manzerra And I. R. Brown ${ }^{1}$ \\ Department of Zoology, University of Toronto, Scarborough Campus, West Hill, Ontario, Canada, M1C 1A4
}

\begin{abstract}
Two characteristic features of the heat shock response, (i) induction of hsp70 protein and (ii) nuclear translocation of constitutive hsc70 and stress-inducible hsp70 protein, were utilized as markers of cellular stress in the rabbit brain. Following a physiologically relevant increase in body temperature of $2.7 \pm .3^{\circ} \mathrm{C}$, nonneuronal cell types, such as ependymal cells and oligodendrocytes, undergo a stress response as assayed by the above criteria. In contrast, several neuronal cell populations required an increased degree of hyperthermic stress $\left(3.4 \pm .2^{\circ} \mathrm{C}\right)$ before exhibiting nuclear translocation of constitutive hsc70 protein. Induction of hsp70 protein was not observed in these neuronal cells at either temperature. The present results suggest that certain neurons in the rabbit brain are buffered against induction of the heat shock response, perhaps due to their high constitutive levels of hsc70 protein. 1996 Academic Press, Inc.
\end{abstract}

\section{INTRODUCTION}

The effects of temperature elevation on the metabolism and structure of mammalian cells has been well documented [1, 2]. Cellular and biochemical features of the classic heat shock (stress) response include (i) an overall decrease in ongoing protein synthesis, (ii) induction of heat shock mRNAs and proteins (hsps), (iii) nuclear translocation of hsps, and (iv) collapse of elements of the cytoskeleton [1, 2]. Induction of hsps, in particular hsp70, by stressful stimuli has attracted considerable attention. Synthesis of hsp70 protein may be triggered in response to increases in denatured proteins which are generated by heat and other forms of stress [reviewed in 3-5]. Hsp70 participates in the recovery of the cell from such perturbations [6]. Recently, hsp70 has been shown to be involved in the in vitro renaturation of denatured proteins [7]. Several studies have supported a role for this stress protein in the protection of mammalian cells from the lethal effects of heat and other stresses [8-14].

\footnotetext{
${ }^{1}$ To whom correspondence and reprint requests should be addressed. Fax. (416) 287-7642.
}

The induction of hsp70 protein in the mammalian nervous system has been reported in response to a variety of neural traumas [reviewed in 15, 16]. The cellular and temporal pattern of hsp70 induction varies depending on the natureand severity of the neural insult. The pattern of hsp70 induction has been found to match the known histopathology of the various traumas, thus establishing the usefulness of hsp70 induction as a marker of cellular stress in the nervous system [reviewed in 16].

A question which needs to be addressed is how one interprets the lack of induction of hsp70 protein in a cell in response to stress $[17,18]$. For example, our previous studies have shown that, following physiologically relevant increases in body temperaturein therabbit, induction of hsp70 mRNA and protein is attenuated in several populations of large neurons compared to the rapid and robust induction which is observed in adjacent glial cells [18-22]. This dampened hsp70 induction in neurons following heat shock has been observed by other laboratories in both in vivo and in vitro studies [reviewed in 21,23 ]. Use of hsp70 protein induction alone as a marker of cellular stress may not be sufficient to predict whether neurons are perturbed following a hyperthermic insult.

In order to investigate the neuronal response to heat shock in more detail, we have analyzed an additional characteristic feature of the cellular stress response, namely, nuclear translocation of constitutive hsc70 and stress-inducible hsp70 proteins. Nuclear translocation of hsp70 protein has been used in tissue culture experiments as an indicator of cellular stress [24]. The combined use in the present study of two markers of cellular stress (hsp70 induction and nuclear translocation of hsc70/hsp70) is unique in the investigation of the in vivo neuronal response to hyperthermia. It provides the means for a more detailed assessment of the neuronal response to stress in the intact mammalian nervous system.

In this report we demonstrate that several populations of neurons require a more severe hyperthermic insult before eliciting a basic feature of the stress re sponse, namely, nuclear translocation of hsc70 protein. In contrast, glial and ependymal cells in the brain in- 
duce hsp70 protein and translocate hsc70/hsp70 to the nucleus following lesser increases in body temperature.

\section{MATERIALS AND METHODS}

Induction of hyperthermia. Body temperature of 1.6-kg male $\mathrm{New}$ Zealand white rabbits $\left(39.6 \pm .2^{\circ} \mathrm{C}\right)$ was elevated by either $2.7 \pm .3^{\circ} \mathrm{C}$ (standard hyperthermic treatment) or by $3.4 \pm .2^{\circ} \mathrm{C}$ (more severe hyperthermic treatment) by the intravenous injection of $100 \mu \mathrm{g} / \mathrm{kg}$ LSD as previously described [25]. Maximal rectal temperature was obtained approximately $1 \mathrm{~h}$ after drug injection and returned to normal temperature by $4 \mathrm{~h}$ [26]. Colonic temperature was monitored with a rectal thermister probe. It has been shown that rectal temperature in rabbits is an accurate representation of body temperature of organs and that rectal temperature and organ temperature increase in parallel during hyperthermia [27, 28]. Induction of heat shock proteins correlated with the drug-induced hyperthermia. Prevention of hyperthermia by injection of the drug into rabbits maintained in a cold room at $4^{\circ} \mathrm{C}$ eliminated the phenomenon; however, other physiological and behavioral effects were still apparent [25, 29]. Animals (four to five per time point) were sacrificed after the appropriate time intervals.

Two-dimensional gel electrophoresis and Western blot procedure Cerebellar protein samples were analyzed by two-dimensional gel electrophoresis according to the method of O'F arrell [30]. Aliquots of protein $(100 \mu \mathrm{g})$ were solubilized in $10 \mathrm{vol}$ of Iysis buffer $(9.5 \mathrm{M}$ urea, 2\% Nonidet P-40, 5\% ampholines (Bio-Rad), $\mathrm{pH} 3-10,5 \% \beta$ mercaptoethanol). I soel ectric focusing in the first dimension was performed in cylindrical gels containing 4\% acrylamide, $9 \mathrm{M}$ urea, 2\% Nonidet $\mathrm{P}-40$, and $2 \%$ ampholines composed of $0.8 \% \mathrm{pH} 4-6,0.8 \%$ $\mathrm{pH} 6-8$, and $0.4 \% \mathrm{pH} 3-10$. Cathode and anode buffers were $20 \mathrm{mM}$ $\mathrm{NaOH}$ (degassed) and $10 \mathrm{mM} \mathrm{H}_{3} \mathrm{PO}_{4}$, respectively. Gels were run for $16 \mathrm{~h}$ at $400 \mathrm{~V}$, followed by $1 \mathrm{~h}$ at $800 \mathrm{~V}$. The cylindrical gels were equilibrated for $1 \mathrm{~h}$ in sample buffer ( $10 \%$ glycerol, $5 \% \beta$-mercaptoethanol, $2.5 \% \mathrm{SDS}$, and $62.5 \mathrm{mM}$ Tris- $\mathrm{HCl}, \mathrm{pH}$ 6.8). The gels were then fused with $0.75 \%$ agarose onto $10 \%$ acrylamide slab gels with a $5 \%$ stacking gel and electrophoresed in the presence of SDS utilizing the discontinuous buffer system of Laemmli [31].

The proteins were then electrophoretically transfered onto nitrocellulose membranes and processed for Western blot analysis. Briefly, blots were treated as follows: four washes of $5 \mathrm{~min}$ in TBST buffer (10 mM Tris, $0.25 \mathrm{M} \mathrm{NaCl}, 0.05 \%$ Tween 20, pH 7.5), blocked for $2 \mathrm{~h}$ at room temperature in 2\% purified BSA in TBST with $0.02 \%$ sodium azide, and then incubated 14-16 h with primary antibody. The antibodies used were as follows: N6F 3-3 (N6) monoclonal antihsp70 and $\mathrm{H} 7$ anti-hsc70/hsp70 antibody (gift from W. Welch) diluted 1:40,000 and 1:50,000, respectively, in 1\% purified BSA in TBST and 1B5 monoclonal anti-hsc70 (gift from A. Laszlo, now available from Stressgen) diluted 1:100,000. The blot was then washed $4 \times 10 \mathrm{~min}$ in 1\% BSA (Sigma grade) in TBST, incubated for $2 \mathrm{~h}$ at room temperature with anti-mouse IgG (1:5,000) or goat anti-rat IgG $(1: 10,000)$ in $1 \%$ BSA (Sigma grade) in TBST and then washed $6 \times 5 \mathrm{~min}$ in TBST. The presence of hsc70 and/or hsp70 was visualized by use of ECL Western blotting detection reagents (Amersham, RPN 2106).

Immunocytochemistry. Brain and spinal cord tissue was prepared as described previously [18]. Frozen cryostat sections $(25 \mu \mathrm{m})$ were incubated for $20 \mathrm{~min}$ at room temperature in $0.1 \mathrm{M} \mathrm{PBS}, \mathrm{pH}$ $7.4,0.2 \%$ Triton X-100, 0.1\% BSA. Sections were then incubated 14$16 \mathrm{~h}$ at room temperature in primary antiserum diluted 1:20,000 for the N6 antibody and 1:500 for the 1B5 antibody. After they were washed two times in buffer for $10 \mathrm{~min}$ the sections were processed with the Vectastain Elite ABC kit (Vector labs). Normal goat serum and biotinylated anti-rat IgG secondary antibody (Vector labs) diluted 1:400 were used with the 1B5 antibody. I mmunocytochemical analysis was performed in triplicate for each set of animals.

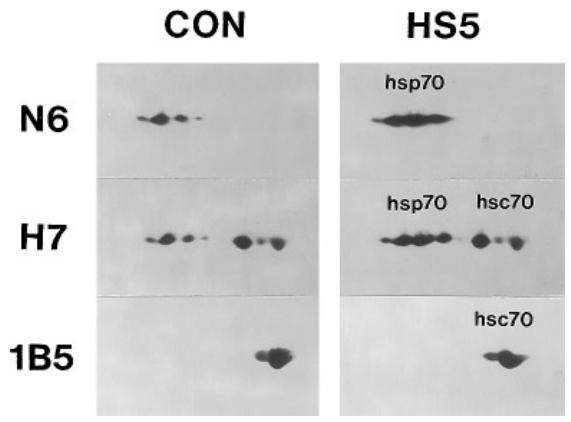

FIG. 1. Specificity of antibodies for constitutive hsc70 and stressinducible hsp70 proteins in the rabbit cerebellum. A two-dimensional Western blot analysis was carried out on control (CON) and 5-h postheat shock (HS5) cerebellar extracts (100 $\mu \mathrm{g})$ immunostained with antibodies specific to either hsp70 [N6F 3-3(N6)] or constitutive hsc70 (1B5). The $\mathrm{H} 7$ antibody was utilized as a reference to identify both sets of isoforms as it reacts to hsc70 and hsp70.

\section{RESULTS}

\section{Specificity of Antibodies for Constitutive hsc70 and Stress-Inducible hsp70 Proteins}

The hsp70 multigene family is composed of members which encode constitutively expressed hsc70 and stress-inducible hsp70 proteins. As shown in Fig. 1 by two-dimensional Western blotting, the $\mathrm{H} 7$ antibody (middle panel) recognized both constitutive hsc70 and stress-inducible hsp70 isoforms in the rabbit cerebellum, while the N6 antibody (top panel) was specific in detecting only hsp70 isoforms. In contrast, the 1B5 antibody (bottom panel) was specific in detecting constitutive hsc70 isoforms with no cross-reactivity to hsp70 isoforms.

The presence of basal levels of hsp70 in the control cerebellum (Fig. 1, CON) was detected by the sensitive $\mathrm{ECL}$ Western blotting system with the N6 antibody. Basal levels of hsp70 protein in unstressed tissues have been reported previously [8, 32-34]. Following hyperthermia (Fig. 1, HS5) the level of the hsp70 isoforms increased in the cerebellum, whereas the level of constitutive hsc70 isoforms, which were detected with the 1B5 antibody, did not.

The profile of hsp70 isoforms detected by Western blotting in Fig. 1 matched that which we have previously observed by two-dimensional analysis of in vivo-labeled cerebellar proteins [25]. Hence, the N6 anti-hsp70 antibody appeared to recognize the full spectrum of hyperthermia-inducible hsp70 isoforms which are synthesized in the cer ebellum in response to physiologically relevant hyperthermia.

\section{I mmunocytochemical Analysis of the Heat Shock}

Response in Nonneuronal Cells of the Rabbit Brain Following Hyperthermia

Having established the specificity of the hsc70 and hsp70 antibodies in the rabbit nervous system (Fig. 
1), an immunocytochemical analysis of the heat shock response was carried out in order to characterize the cellular stress response to hyperthermia. Several neuronal and nonneuronal cell types were compared in this analysis. Two characteristic features of a heat shock response, (i) induction of hsp70 protein and (ii) nuclear translocation of constitutive hsc70 and stress-inducible hsp70, were utilized as markers of cellular stress.

In control animals (Fig. 2A), a cytoplasmic localization of constitutive hsc70 was detected in ependymal cells of the choroid plexus (see cell indicated by arrow) utilizing the constitutive hsc70-specific antibody 1B5. Following a physiologically relevant increase in body temperature of $2.7 \pm .3^{\circ} \mathrm{C}$ (Fig. $2 \mathrm{C}$ ), translocation of constitutive hsc70 protein to the nucleus was observed followed by a return to the cytoplasm by $5 \mathrm{~h}$ post-heat shock (Fig. 2E). No apparent increase in constitutive hsc70 protein was observed in ependymal cells following heat shock (compare Figs. $2 \mathrm{~A}$ and $2 \mathrm{E}$ ). Previous in vitro studies have also shown that constitutive hsc70 protein undergoes a nuclear translocation following heat stress in cultured mammalian cells [1]. Using the hsp70-specific N6 antibody, a cytoplasmic distribution of basal hsp70 was observed in ependymal cells in control animals (Fig. 2B), with a translocation of hsp70 to the nucleus following $1 \mathrm{~h}$ heat shock (Fig. 2D). By $5 \mathrm{~h}$ post-heat shock (Fig. 2F), hsp70 levels had increased greatly compared to those of controls (Fig. 2B) and the signal was localized to the cytoplasm.

An immunocytochemical analysis of the heat shock response in the glial-enriched corpus call osum was also carried out utilizing the hsp70-specific N6 antibody (Fig. 3). Oligodendrocytes in this brain region exhibited an induction of hsp70 protein following hyperthermia (compare control, Fig. 3A, with $5 \mathrm{~h}$ post-heat shock, Fig. 3D). Initially, hsp70 protein was observed in the cytoplasm of oligodendrocytes (Fig. 3B) and rapidly translocated to the nucleus (Fig. 3C) followed by a cytoplasmic localization at $5 \mathrm{~h}$ post-heat shock (Fig. 3D). The lag time in the nuclear accumulation of hsp70 in oligodendrocytes in comparison to ependymal cells is likely due to the time required to synthesize hsp70. E pendymal cells already contain basal levels of hsp70 protein before heat shock and translocation of the endogenous protein was rapid.

These results indicate that in response to hyperthermia of $2.7 \pm .3^{\circ} \mathrm{C}$, ependymal cells and ol igodendrocytes in the rabbit brain demonstrate two characteristic features of a stress response, namely, induction of hsp70 protein and translocation of hsc70/hsp70 into the nucleus.

Effect of Hyperthermia on the Intracellular Localization of Constitutive hsc70 Protein in Neuronal Cell Types

Previous studies have shown that in response to hyperthermia, several neuronal cell populations, both in vivo and in vitro, show a dampened hsp70 induction response compared to glial cells [21, 23]. High constitutive level s of hsc70 protein have been reported in these neuronal cells which may play a role in dampening hsp70 induction [18]. Since ependymal cells in the rabbit brain translocate constitutive hsc70 to the nucleus at $1 \mathrm{~h}$ following hyperthermia of $2.7 \pm .3^{\circ} \mathrm{C}$, we next determined if a nuclear translocation of hsc70 protein occurred in neurons in response to a similar hyperthermic treatment. Figure 4 shows five neuronal cell populations at the 1-h hyperthermic time point immunostained with the hsc70-specific antibody, 1B5. Nuclear translocation of hsc70 protein was not apparent in theseneuronal cell populations including Purkinje, cortical, deep cerebellar, thalamic, and granule neurons of the dentate gyrus (Figs. $4 \mathrm{~A}-4 \mathrm{E}$, respectively). The hsc70 protein remained in the neuronal cytoplasm of 1-h hyperthermic animals. Similar results were obtained at $\frac{1}{2} \mathrm{~h}$ heat shock and at 1 and $2 \mathrm{~h}$ post-heat shock (data not shown). In a previous study, the induction of hsp70 protein was not detected in Purkinje neurons of the cer ebellum following a physiological temperature increase [18]. Similarily, no induction of hsp70 protein was detected in the neuronal populations examined here (data not shown).

The lack of nuclear translocation of constitutive hsc70 protein was not observed in all neuronal cell types. Immunocytochemistry with the constitutive hsc70-specific 1B5 antibody demonstrated high levels of hsc70 protein in motor neurons (arrow) of the spinal cord of the control rabbit (indicated by arrow in Fig. 5A). Interestingly, hsc70 appears to be present in the nucleus of control motor neurons in contrast to the other neural cell types shown in Fig. 4. In 1-h hyperthermic animals, translocation of hsc70 protein to the nuclei of spinal cord motor neurons was apparent (Fig. 5B) followed by a return to the control pattern at $5 \mathrm{~h}$ post-heat shock (Fig. 5C). The transient nuclear relocalization of the constitutive hsc70 protein at $1 \mathrm{~h}$ suggested that these neurons were stressed by the hyperthermic treatment and exhibited one of the classic features of the heat shock response. To determine whether these neurons also induced hsp70 protein, an immunocytochemical analysis of 5 -h post-heat shock spinal cord tissue was undertaken utilizing the inducible hsp70-specific antibody N6 (Fig. 5D). Induction of hsp70 protein was not detected in these motor neurons (outlined by arrows in Fig. 5D); however a robust induction was noted in neighboring glial cells (arrowheads).

Nuclear Translocation of hsc70 Protein in Neurons Following an Increased Degre of Hyperthermic Stress

Our standard hyperthermic conditions did not result in the nuclear translocation of hsc70 protein in several 

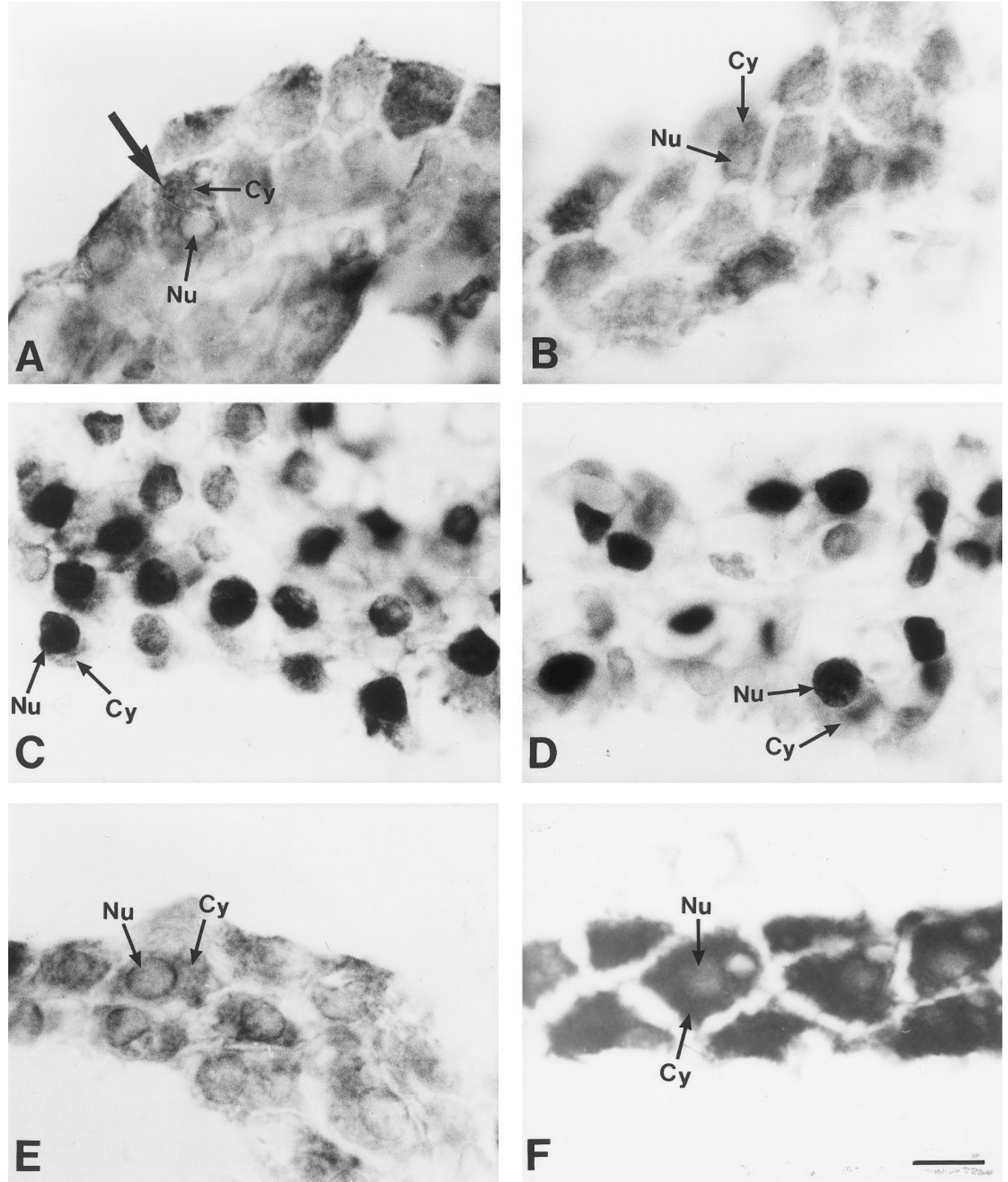

FIG. 2. Immunocytochemical analysis of the heat shock response in ependymal cells of the choroid plexus following hyperthermia. The induction and translocation of constitutive hsc70 (A,C,E) and stress-inducible hsp70 protein (B,D,F) were investigated in ependymal cells in the rabbit brain of control $(A, B)$, heat shock $(C, D)$, and 5-h post-heat shock $(E, F)$ animals. The antibodies used were shown in $F$ ig. 1 to be specific in recognizing either constitutive hsc70 protein (1B5 antibody) or stress-inducible hsp70 protein (N6 antibody). Bar, 10.9 um. $\mathrm{Nu}$, nucleus; Cy, cytoplasm; arrow, ependymal cell. 

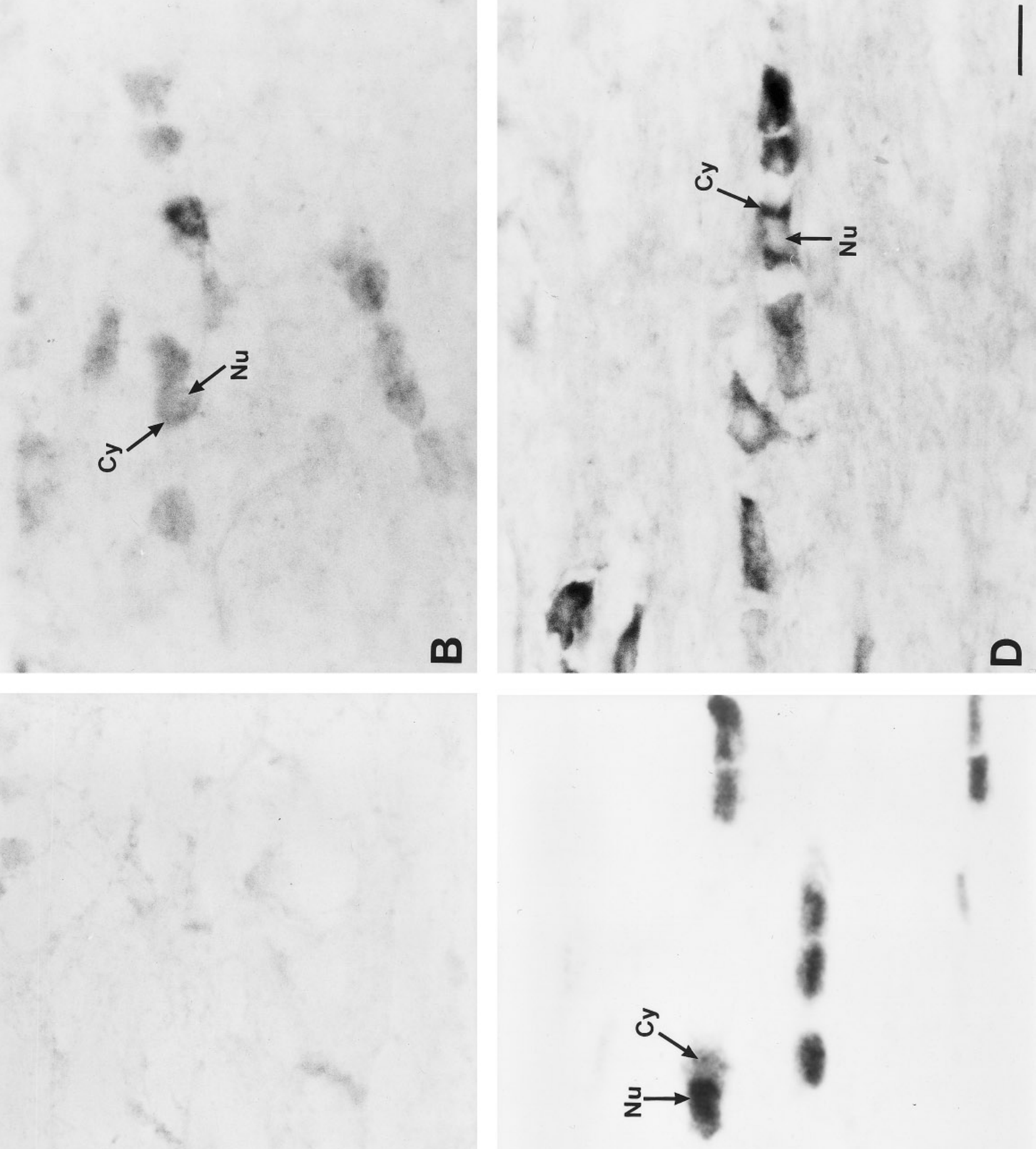

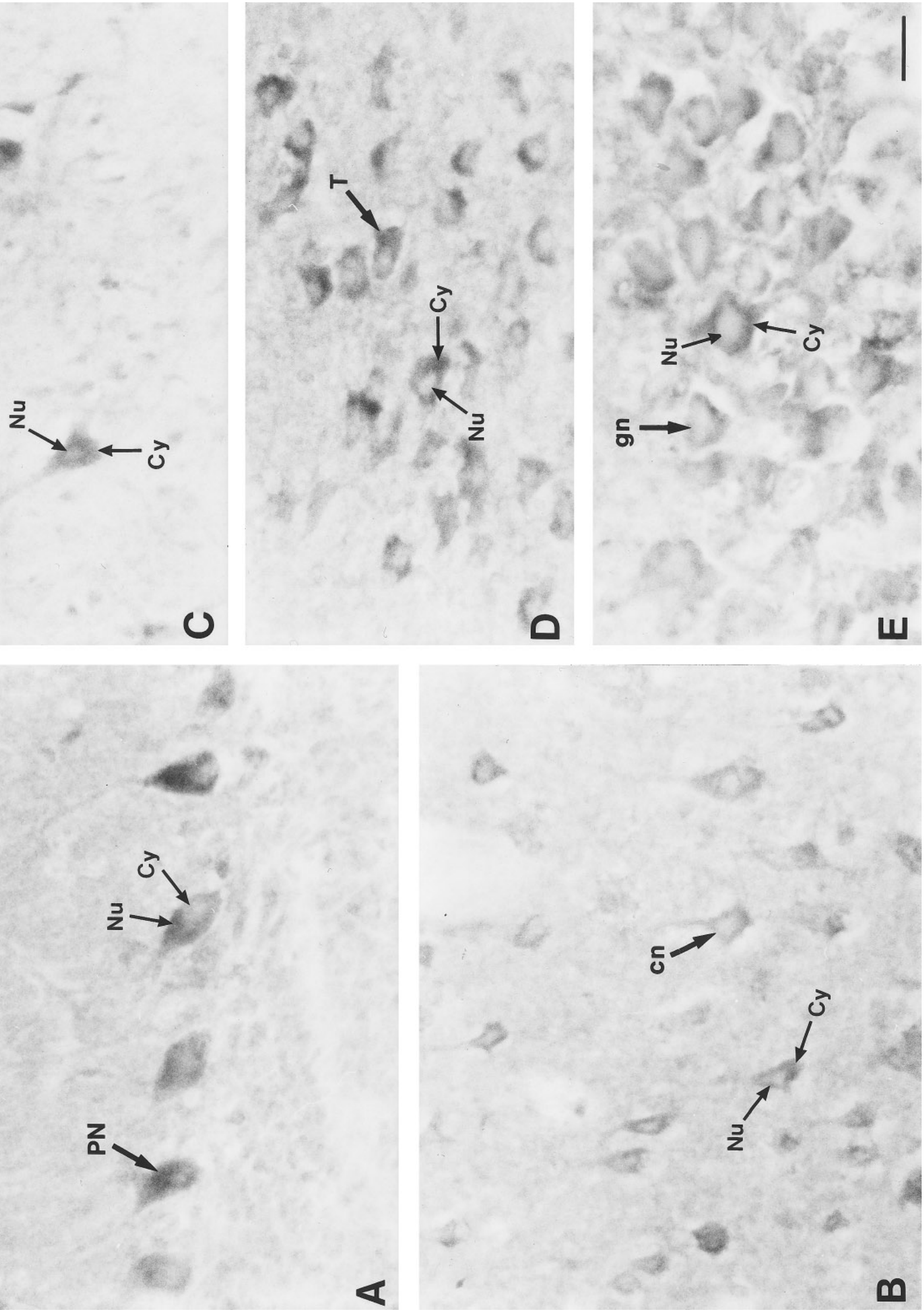

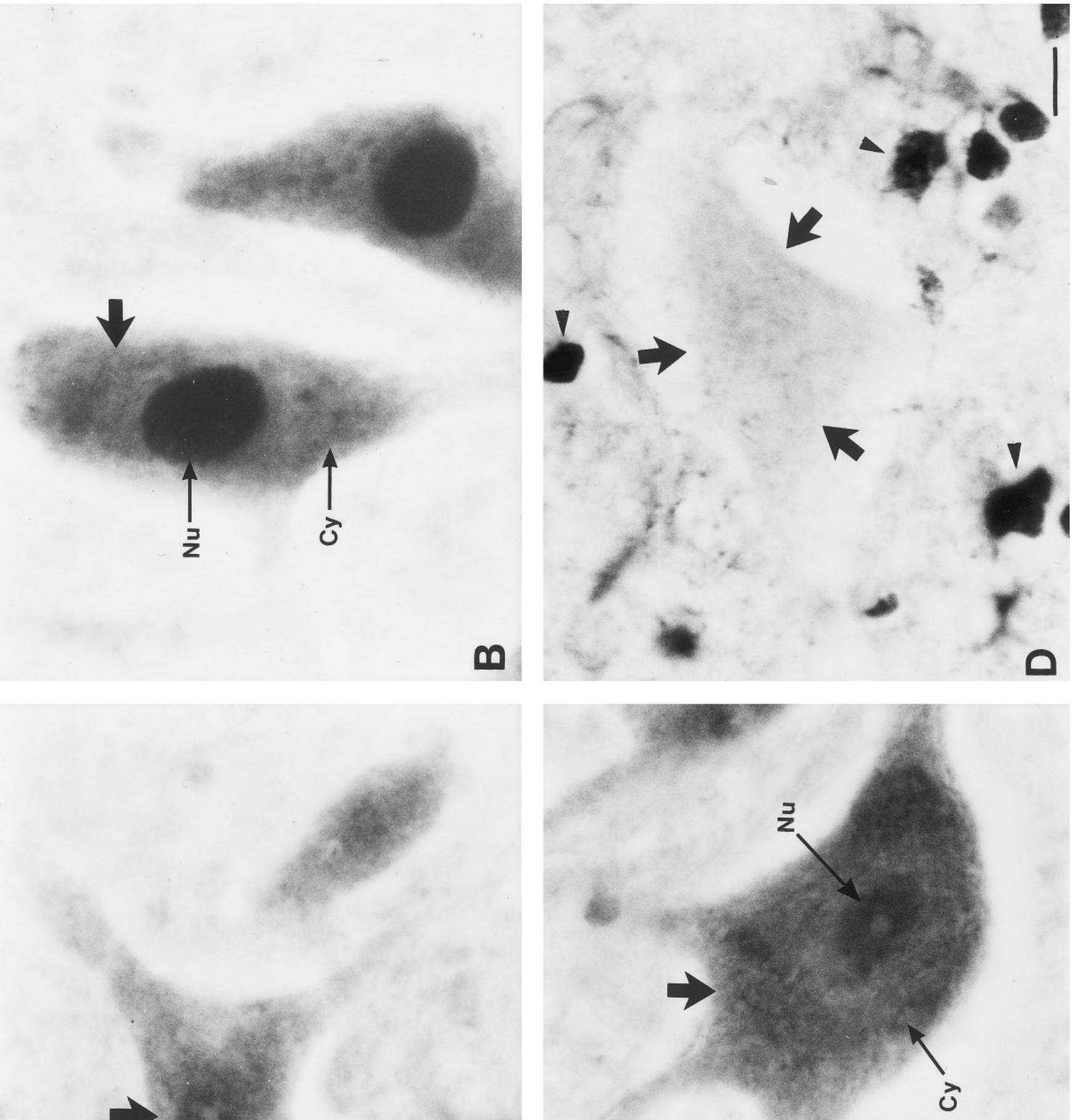
neuronal cell types (Fig. 4), with motor neurons of the spinal cord being the exception (Fig. 5). The effect of increasing the degree of hyperthermic stress from 2.7 $\pm .3^{\circ} \mathrm{C}$ to $3.4 \pm .2^{\circ} \mathrm{C}$ over normal body temperature was next examined (Fig. 6). The increased hyperthermic stress resulted in the nuclear translocation of hsc70 protein in thalamic neurons of the anterior dorsal thalamus (Fig. 6B), cortical neurons of the cerebral cortex (Fig. 6C), and granule neurons of the dentate gyrus (Fig. 6D) in 1-h hyperthermicanimals. Nuclear translocation of hsc70 protein was also observed in some, but not all, Purkinje neurons in the cerebellum (Fig. 6A).

To investigate whether the increased level of hyperthermia triggered neuronal induction of hsp70, an immunochemical analysis was undertaken with the hsp70-specific N6 antibody (Fig. 7). Despitethe nuclear translocation of hsc70 in neurons which was observed following the more severe hyperthermia (Fig. 6), neuronal induction of hsp70 was not apparent in Purkinje neurons of the cerebellum (Figs. 7A and 7B) or granule neurons of the dentate gyrus (Figs. 7C and 7D). An induction of hsp70 protein in adjacent glial cells was observed in the cerebellum and dentate gyrus (indicated by arrowheads).

\section{DISCUSSION}

Studies on the cellular stress response in mammalian cells have focused primarily on the induction of hsp70. This protein is a useful marker of cellular stress in many cell types; however, previous studies both in vivo and in vitro haveindicated that induction of hsp70 is dampened in several neuronal cell populations following heat shock compared to glial cells [21, 23]. In this report, an additional characteristic feature of the heat shock response, namely, nuclear translocation of heat shock protein, was used as an indicator of cellular stress to better characterize the in vivo neuronal response to hyperthermia.

A physiologically relevant increase in body temperature of rabbits of $2.7 \pm .3^{\circ} \mathrm{C}$ resulted in the induction of hsp70 and nuclear translocation of hsc70/hsp70 in nonneuronal cell types (ependymal cells and oligodendrocytes). Heat shock results in a variety of perturba- tions in cellular morphology and metabolic activities $[2,35]$. The induction of hsp70 and nuclear translocation of hsc70/hsp70 following heat stress is believed to facilitate repair processes [1,6, 36-38]. The observation of these two characteristic features of a heat shock response in the nonneuronal cell types indicates that they are stressed by the hyperthermic insult.

Examination of several neuronal cell populations including Purkinje, hippocampal, thalamic, and cortical neurons revealed neither induction of hsp70 nor nuclear translocation of hsc70 following el evation of body temperature by $2.7 \pm .3^{\circ} \mathrm{C}$. Cellular differences in the induction of the heat shock response in the brain are unlikely to be a result of differential heating since glial cells which demonstrated features of a heat shock response were found adjacent to nonresponsive neuronal cells (see Figs. 5 and 7). The lack of a heat shock response in these neuronal cell populations, in contrast to ependymal cells and oligodendrocytes, suggests that these cells may be buffered against a physiologically relevant temperature increase. A different response was noted in motor neurons of the spinal cord. Nuclear translocation of hsc70 was observed in these neurons indicating that these cells may be more sensitive to the hyperthermic stress than the other neurons examined in this study.

We have suggested that several populations of large neurons in the rabbit brain may be buffered against physiologically rel evant increases in body temperature, due to their high constitutive levels of hsc70 protein $[18,20]$. In addition to hsc70, neurons express high constitutive levels of hsp90 mRNA and protein which may also contribute to this buffering [39, 40]. Cells which have elevated levels of hsps, as a result of either priming by a sublethal heat shock [37, 38, 41] or transfection with hsp70 cDNA [42, 43], show a substantial reduction in phenomena which are associated with the heat shock response, such as transient inhibition of ongoing protein synthesis [37, 42,43], cytoskel etal collapse [38], snRNP disruption [38, 41], and nuclear protein aggregation $[44,45]$. The reduction in these phenomena was apparent without induction of hsp70. In certain populations of large neurons, constitutively expressed hsc70 and hsp90 protein may be able to accom-

FIG. 3. Induction and nuclear translocation of hsp70 protein in oligodendrocytes of the hyperthermic rabbit brain. The hsp70-specific $\mathrm{N} 6$ antibody was used in an immunocytochemical analysis of the heat shock response in oligodendrocytes of the rabbit corpus callosum. Bar, 10.9 um. (A) control, (B) heat shock, (C) 1 h post-heat shock, (D) 5 h post-heat shock; Nu, nucleus; Cy, cytoplasm.

FIG. 4. Effect of hyperthermia on the intracellular localization of constitutive hsc70 protein in neuronal cell types. The hsc70-specific antibody 1B5 was utilized to investigate the nuclear translocation of hsc70 protein in neurons of the cerebellum (A,C), cerebral cortex (B), anterior dorsal thalamus (D), and dentate gyrus (E) following $1 \mathrm{~h}$ hyperthermia. For A-D, Bar, $26.4 \mu \mathrm{m}$. For E, bar, $10.9 \mu \mathrm{m}$. cn, cortical neuron; Cy, cytoplasm; DCN, deep cerebellar nuclei; gn, granule neuron; Nu, nucleus; PN, Purkinje neuron; T, thalamic neuron.

FIG. 5. Nuclear translocation of constitutive hsc70 protein in motor neurons of the spinal cord following hyperthermia. I mmunocytochemical analysis was carried out with the constitutive hsc70-specific $1 B 5$ antibody $(A, B, C)$ and stress-inducible hsp70-specific N6 antibody (D) in the spinal cord of control (A), heat shock (B), and 5-h post-heat shock (C,D) rabbits. Bar, $10.9 \mu \mathrm{m}$. Nu, nucleus; Cy, cytoplasm; arrows, motor neurons; arrowheads, glia. 


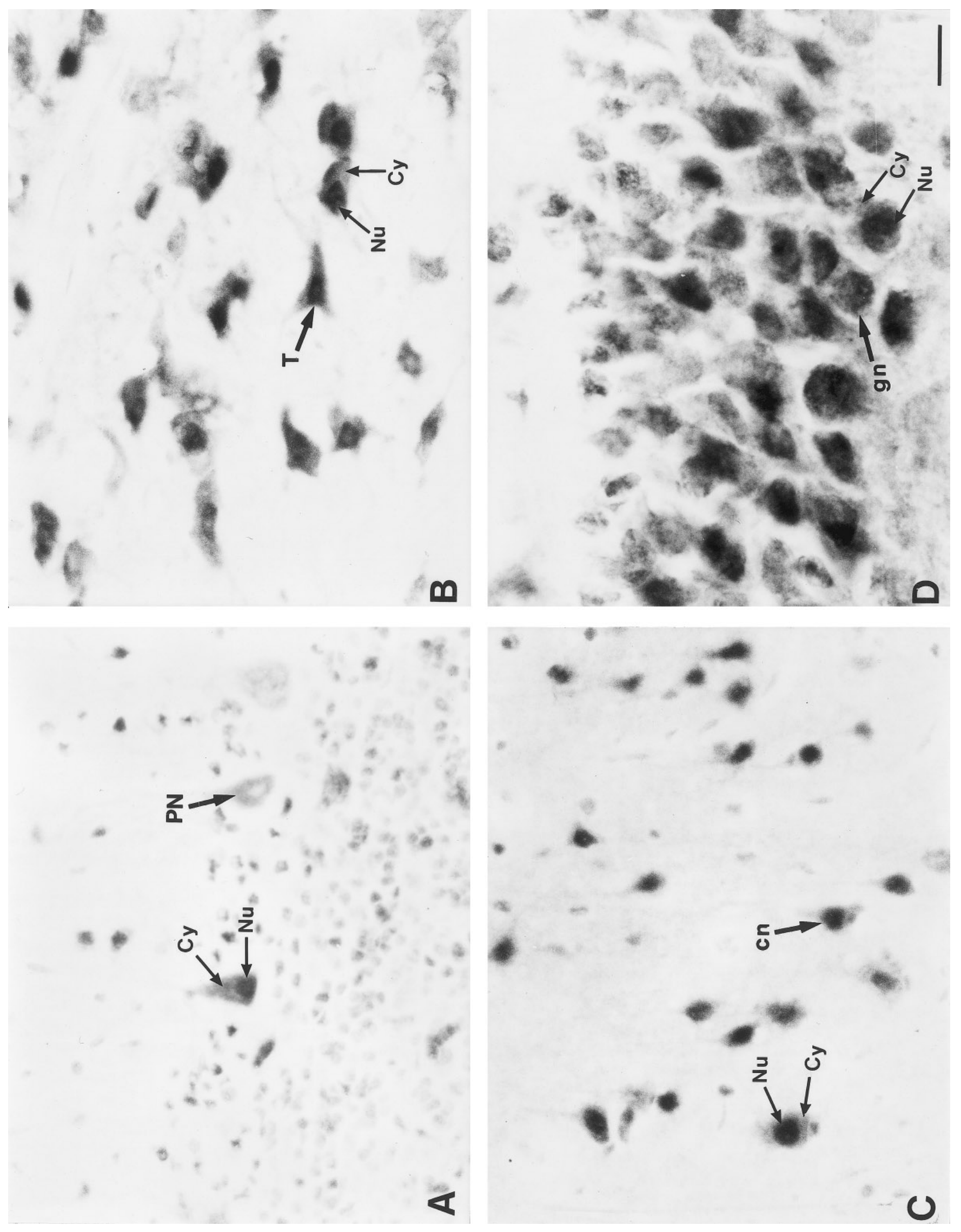



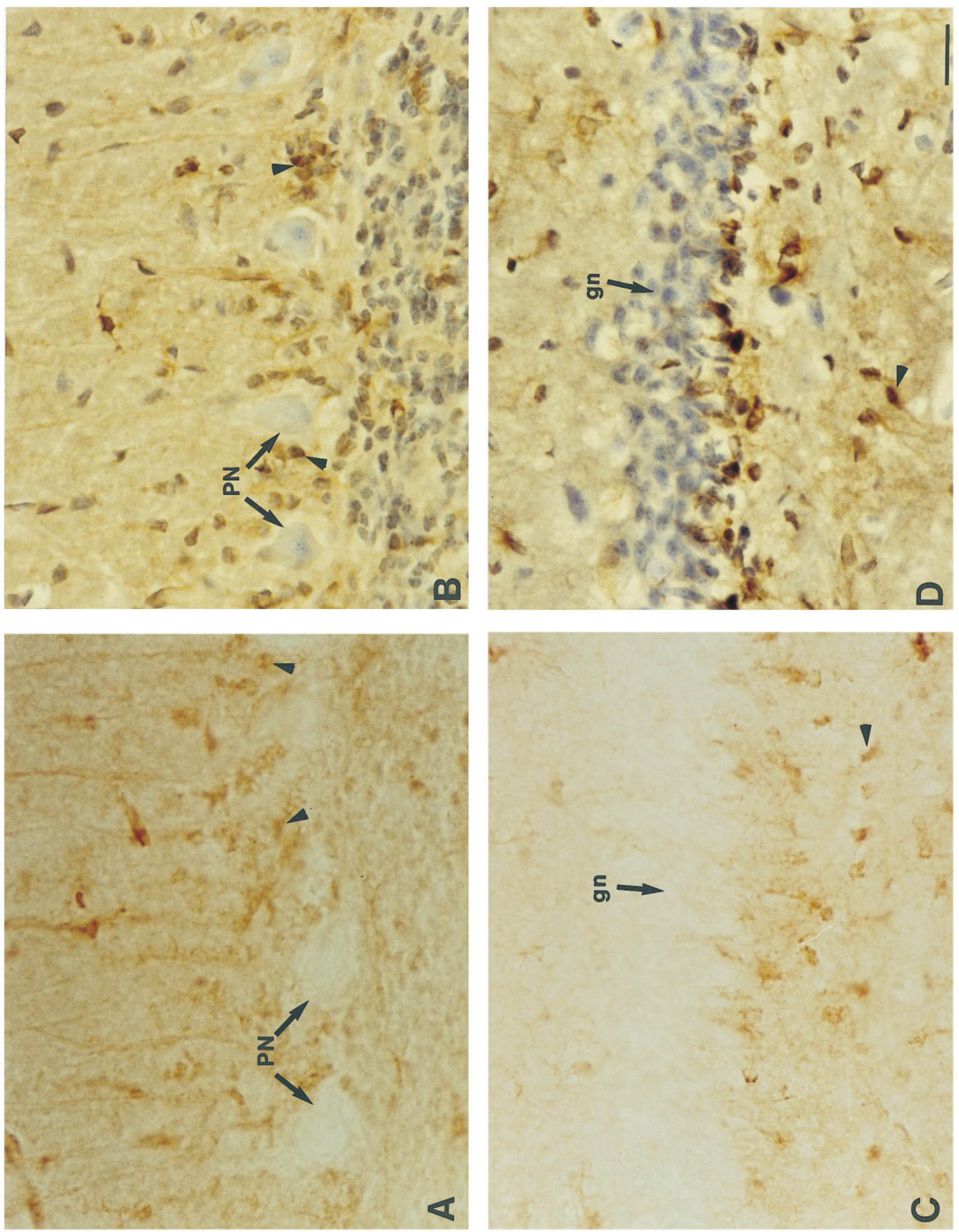
modate the cellular perturbations which arise due to a physiologically relevant hyperthermic stress of $2.7 \pm$ $.3^{\circ} \mathrm{C}$ without induction of hsp70 protein. This avoidance of the classic heat shock response after mild stress could have beneficial effects for those neurons since potentially negative features of the stress response, such as transient inhibition of overall protein synthesis, might not be triggered.

A study by Marcuccilli et al. [46] suggested that the lack of hsp70 induction in cultured hippocampal neurons compared to glial cells following heat stress was not related to high constitutive levels of hsc70 or hsp90 protein since both types of cultured cells were found to have similar levels of these proteins. These results contrast with in vivo studies which have demonstrated high constitutive levels of hsc70 and hsp90 mRNA and protein in several populations of neurons compared to glial cells [18-20, 39, 40, 47-50]. Steady-state levels of hsc70 and hsp90 mRNA and protein are increased three to sixfold in rapidly dividing (serum-stimulated) tissue culture cells compared to growth-arrested cells [51-53]. Since glial cells in culture are rapidly dividing in contrast to cultured postmitotic neuronal cells, this may account for the apparent discrepancies in hsc70 and hsp90 levels between in vitro and in vivo studies.

Cultured cerebral cortical neurons have been found to be more susceptible to heat-induced cell damage than cultured astrocytes [54]. It was suggested that the sensitivity of these cells may be due to their failure to induce hsp70 protein after injury. However, that investigation and most in vitro studies [23] have employed supraphysiological increases in temperature of $+6-$ $8^{\circ} \mathrm{C}$. Increases of that magnitude in vivo result in death of the animal; thus, they are not physiologically relevant. No morphological evidence of neuronal cell death or damage was observed following physiologically relevant hyperthermic stress in vivo [55]. These observations emphasize that care must be taken in extrapolating tissue culture results to the intact animal.

Our results suggest that there are cell type differences in the temperature set point required for induction of the heat shock response in the mammalian nervous system. We examined the heat shock response in rabbit brain following a more severe hyperthermic insult where body temperature was elevated by $3.4 \pm$ $.2^{\circ} \mathrm{C}$. Translocation of hsc70 protein into the nucleus was then observed in those neurons which did not translocate hsc70 following the $2.7 \pm .3^{\circ} \mathrm{C}$ increase. Thus, these neurons are capable of initiating a basic feature of a stress response; however, a higher temperature increase was required. It appears that a body temperature of $43^{\circ} \mathrm{C}$ in rabbits is needed to induce a neuronal response at the level of nuclear translocation of hsc70.

Studies have shown that the heat shock response in cells is dependent on the degree of stress and on levels of preexisting hsps [37, 43, 56]. Our results indicate that the neuronal heat shock response may occur in stages depending on the level of stress on individual cell populations. Following a fever-like temperature increase of $2.7 \pm .3^{\circ} \mathrm{C}$, a neuronal response is not observed, perhaps due to high levels of preexisting hsps. In response to a higher degree of hyperthermic stress of $3.4 \pm .2^{\circ} \mathrm{C}$, neuronal cells undergo a partial heat shock response, namely, nuclear translocation of hsc70 protein. Severe stress, such as ischemia, results in a full heat shock response in neurons involving induction of hsp70 protein [57]. Among the glial cell populations, a robust induction of hsp70 mRNA was observed in oligodendrocytes and microglia with no detectable re sponse in GFAP-positive astrocytes in the forebrain [58]. Induction of hsp70 mRNA and protein was also observed in Bergmann glial cells of the rabbit cerebellum [18].

In this study, induction of hsp70 protein was not observed in several populations of neurons. Lack of hsp70 protein induction in neurons following hyperthermic stress has been reported previously [reviewed in 21,23$]$. Recent in vitro studies have offered possible explanations for this dampened hsp70 induction in neurons following heat shock. In Y 79 retinoblastoma cells, diminished hsp70 induction appears to be the result of a chromatin-mediated effect which hampers access of the heat shock transcription factor (HSF 1) to binding sites in the neuronal hsp70 promoter [59]. In cultured hippocampal neurons, the deficient heat shock response has been attributed to a lack of expression of HSF 1 protein [46]. These mechanisms seem unlikely explanations for the attenuated neuronal hsp70 induction which is observed in vivo since neuronal induction of hsp70 is apparent in vivo in response to severe traumas $[15,16]$. For example, focal ischemia results in a

FIG. 6. Nuclear translocation of constitutive hsc70 protein in neurons following a more severe hyperthermic stress. The hsc70-specific antibody 1B5 was utilized to investigate the nuclear translocation of hsc70 in neurons of the cerebellum (A), the anterior dorsal thalamus (B), the cerebral cortex (C), and the dentate gyrus (D) following an increased degree of hyperthermic stress (see Materials and Methods). For A-C, bar, $26.4 \mu \mathrm{m}$. For D, bar, $10.9 \mu \mathrm{m}$. cn, cortical neuron; Cy, cytoplasm; gn, granule neuron; Nu, nucleus; PN, Purkinje neuron; T, thalamic neuron.

FIG. 7. Induction of hsp70 protein following severe hyperthermia. An immunocytochemical analysis of stress-inducible hsp70 in the cerebellum $(A, B)$ and dentate gyrus $(C, D)$ was undertaken with the $\mathrm{N} 6$ antibody following elevation of body temperature by $3.4 \pm .2^{\circ} \mathrm{C}$. Tissue sections were counterstained with cresyl violet for cellular identification (B and D). Bar, $26.4 \mu \mathrm{m}$. gn, granule neuron; PN, Purkinje neuron, arrowhead, glia. 
predominantly neuronal induction of hsp70 which is mediated by HSF 1 activation, [60, 61]. These ischemic studies indirectly suggest the presence of HSF 1 in the responding neuronal cell populations. However, investigations of potential cell-type differences in HSF 1 levels in vivo are required and could be addressed by immunocytochemical localization of HSF 1 . In vivo activation of heat shock transcription factor HSF 1 has been reported in the rabbit brain following physiologically relevant increase in body temperature [62].

Our two-dimensional Western blot analysis of rabbit cerebellar proteins demonstrated that basal levels of hsp70 isoforms are present in the control animal and that these isoforms are elevated following hyperthermia. Whether the multiple hsc70 and hsp70 isoforms observed represent the products of different genes and/ or posttranslational modifications is unclear. Multiple isoforms have been observed in other mammalian systems both in vivo and in vitro [1, 63, 64]. We have not determined whether an increased degree of hyperthermia alters the spectrum of hsp70 isoforms; however, the $\mathrm{N} 6$ antibody employed in this study appears capable of detecting the full spectrum of hsp70 isoforms induced foll owing a physi ol ogically rel evant hyperthermia. Why several inducible hsp70 isoforms exist is still unresolved; however, it may allow for isoforms with similar functions to betargeted to different cells/organelles or it might reflect the presence of hsp70 isoforms with functional variations. Since the anti-hsp70 antibody utilized in this study did not differentiate among isoforms, it was not possible to determine by immunocytochemical analysis if different hsp70 isoforms are expressed in different cell types.

In summary, we have utilized two characteristic features of the heat shock response, (i) induction of hsp70 protein and (ii) nuclear translocation of hsc70/hsp70, as indicators of cellular stress to investigate the in vivo neuronal response to hyperthermic stress. Our results suggest that certain neuronal cell populations in the rabbit brain may have an intrinsic buffering capacity to physiologically relevant heat stress which manifests as an attenuated hsp70 induction response.

We thank William Welch and Andre Laszlo for the generous donation of antibodies (N6F 3-3 and H7 from W.W. and 1B5 from A.L.). We thank Sheila Rush for proofreading the manuscript. This work is funded by grants to I.R.B. from MRC Canada.

\section{REFERENCES}

1. Welch, W. J ., and Sunhan, J. P. (1986) J . Cell Biol. 103, 20352052.

2. Laszlo, A. (1992) Cell Proliferation 25, 59-87.

3. Morimoto, R.I., Tissieres, A., and Georgopoulos, C. (1990) Stress Proteins in Biology and Medicine, Cold Spring Harbor Laboratory Press, Cold Spring Harbor, NY.

4. Nover, L. (1991) Heat Shock Response, CRC Press, Boca Raton.
5. Morimoto, R.I., Tissieres, A., and Georgopoulos, C. (1994) The Biology of the Heat Shock Proteins and Molecular Chaperones, Cold Spring Harbor Laboratory Press, Cold Spring Harbor, NY.

6. Parsell, D. A., and Lindquist, S. (1993) Annu. Rev. Genet. 27, 437-496.

7. Nimmesgern, E., and Hartl, F. U. (1993) FEBS Lett. 331, 2530.

8. Barbe, M. F., Tytell, M., Gower, D. J ., and Welch, W. J . (1988) Science 214, 1817- 1820.

9. J ohnston, R. N., and Kucey, B. L. (1988) Science 242, 15511554.

10. Riabowal, K. T., Mizzen, L. A., and Welch, W. J . (1988) Science 242, 433- 436.

11. Angelidis, C. E., Lazaridis, I., and Pagoulatis, G. N. (1991) Eur. J. Biochem. 199, 35- 39.

12. Li, G. C., Li, L., Liu, Y-K., Mak, J.Y., Chen, L., and Lee, W. M. F. (1991) Proc. Natl. Acad. Sci. USA 88, 1681- 1685.

13. Uney, J . B., Kew, J . N. C., Staley, K., Tyers, P., and Sofroniew, M. V. (1993) FEBS Lett. 334, 313- 316.

14. Mailhos, C., Howard, M. K., and Latchman, D. S. (1994) J . Neurochem. 63, 1787-1795.

15. Brown, I. R. (1990) J . Neurosci. Res. 27, 247- 255.

16. Mayer, J ., and Brown, I. R. (1994) Heat Shock Proteins in the Nervous System, Academic Press, San Diego.

17. Nishimura, R. N., Dwyer, B. E., Clegg, K., Cole, R., and deVellis, J . (1991) Mol. Brain Res. 9, 39-45.

18. Manzerra, P., Rush, S. J ., and Brown, I. R. (1993) J . Neurosci. Res. 36, 480- 490.

19. Manzerra, P., and Brown, I. R. (1992) Neurochem. Res. 17, 559564.

20. Manzerra, P., and Brown, I. R. (1992) J . Neurosci. Res. 31, 606615.

21. Brown, I. R. (1994) in Heat Shock Proteins in the Nervous System (Mayer, J ., and Brown, I. R., Eds.), pp. 31-53, Academic Press, San Diego.

22. Foster, J. A., Rush, S. J ., and Brown, I. R. (1995) J . Neurosci. Res. 41, 603-612.

23. Dwyer, B. E., and Nishimura, R. N. (1994) in Heat Shock Proteins in the Nervous System (Mayer, J ., and Brown, I. R., Eds.), pp. 101-121, Academic Press, San Diego.

24. Laszlo, A., Davidson, T., Hu, A., Landry, J ., and Bedford, J . (1993) Int. J . Radiat. Biol. 63, 569-581.

25. Cosgrove, J. W., and Brown, I. R. (1983) Proc. Natl. Acad. Sci. USA 80, 569- 573.

26. Heikkila, J . J ., and Brown, I. R. (1979) Neurochem. Res. 4, 763776.

27. Kluger, M. J ., Gonzalez, R. R., and Stolwijk, A. J . (1973) Am. J . Physiol. 224, 130- 135.

28. Baker, M. A. (1979) Sci. Am. 240, 130- 139.

29. Manzerra, P., and Brown, I. R. (1990) Neurochem. Res. 15, 5359.

30. O'Farrell, P. H. (1975) J . Biol. Chem. 250, 4007- 4021.

31. Laemmli, U. K. (1970) Nature 227, 680-685.

32. Locke, M., Noble, E. G., and Atkinson, B. G. (1991) Am. J . Physiol. 261, C774-C779.

33. Tanguay, R. M., Wu, Y., and Khandjian, E. W. (1993) Dev. Genet. 14, $112-118$.

34. Vamvakopoulos, N. O. (1993) Mol. Cell. Endocrinol. 98, 49-54.

35. Welch, W. J . (1990) in Stress Proteins in Biology and Medicine (Morimoto, R. I., Tissieres, A., and Georgopoulos, C., Eds.), pp. 
223-278, Cold Spring Harbor Laboratory Press, Cold Spring Harbor, NY.

36. Pelham, H.R. B. (1984) EMBO J . 3, 3095- 3100.

37. Mizzen, L. A., and Welch, W. J . (1988) J . Cell Biol. 106, 11051116.

38. Welch, W. J ., and Mizzen, L. A. (1988) J . Cell Biol. 106, 11171130.

39. Quraishi, H., and Brown, I. R. (1995) Exp. Cell Res. 219, 358363.

40. Quraishi, H., Rush, S. J ., and Brown I. R. (1996) J . Neurosci. Res. 43, 335- 345.

41. Yost, H. J ., and Lindquist, S. (1986) Cell 45, 185- 193.

42. Liu, R. Y., Li, X., Li, L., and Li, G. C. (1992) Cancer Res. 52, 3667- 3673.

43. Mosser, D. D., Duchaine, J ., and Massie, B. (1993) Mol Cell. Biol. 13, 5427- 5438.

44. Borrelli, M. T., Stafford, D. M., Rausch, C. M., Lee, Y.J ., and Corry, P. M. (1993) J . Cell. Physiol. 156, 171- 181.

45. Stege, G.J .J ., Brunsting, J . F., Kampinga, H. H., and Konings, A. W. T. (1995) J . Cell. Physiol. 164, 579-586.

46. Marcuccilli, C.J ., Mathur, S. K., Morimoto, R. I., and Miller, R. J . (1996) J . Neurosci. 16, 478- 485.

47. Pardue, S., Groshan, K., Raese, J.D., and Morrison-Bogorad, M. (1992) Neurobiol. Aging 13, 661-672.

48. Itoh, H., Tashima, Y., Eishi, Y., and Okeda, R. (1993) Int. J . Biochem. 25, 93- 99.

49. Gass, P., Schroder, H., Prior, P., and Kiessling, M. (1994) Neurosci. Lett. 182, 188- 192.

Received May 31, 1996

Revised version received August 12, 1996
50. Morrison-Bogorad, M., Pardue, S., Mclntire, D. D., and Miller E. K. (1994) J . Neurochem. 63, 857-867.

51. Sorger, P. K., and Pelham H. R. B. (1987) EMBO J . 6, 993- 998.

52. Takenaka, I. M., and Hightower, L. E. (1992) J . Cell. Physiol. 152, 568- 577.

53. Takenaka, I. M., and Hightower, L. E. (1993) J . Cell. Physiol. 155, 54- 62.

54. Nishimura, R. N., Dwyer, B. E., Vinters, H. V., deVellis, J ., and Cole, R. (1991) Neuropathol. Appl. Neurobiol. 17, 139- 147.

55. McCabe, T., and Simon, R. P. (1993) Neurosci. Lett. 159, 163165.

56. DiDomenico, B.J ., Bugaisky, G.E., and Lindquist, S. (1982) Cell 31, 593-603.

57. Nowak, T. S., Suga, S., and Saito, N. (1994) in Heat Shock Proteins in the Nervous System (Mayer, J ., and Brown, I. R., Eds.), pp. 54-81, Academic Press, San Diego.

58. Foster, J . A., and Brown, I. R. (1996) Mol. Brain Res. (in press).

59. Mathur, S. K., Sistonen, L., Brown, I. R., Murphy, S. P., Sarge, K. D., and Morimoto, R. I. (1994) Proc. Natl. Acad. Sci. USA 91, 8695-8699.

60. Higashi, T., Takechi, H., U emura, Y., Kikuchi, H., and Nagata, K. (1994) Brain Res. 650, 239- 248.

61. Higashi, T., Nakai, A., Uemura, Y., Kikuchi, H., and Nagata, K. (1995) Mol. Brain Res. 34, 262- 270.

62. Brown, I. R., and Rush, S.J . (1996) J . Neurosci. Res. 44, 5257.

63. Hotchkiss, R., Nunnally, I., Lindquist, S., Taulier, J ., Perdrizet, G., and Karl, I. (1993) Am. J . Physiol. 265, R1447-R1457.

64. Gutierrez, J. A., and Guerriero, V., J r. (1995) Biochem. J . 305, 197- 203. 